Revista de la red interuniversitaria de estudios sobre las literaturas rioplatenses contemporáneas en Francia

17 | 2017

Hermetismo programático en la literatura rioplatense contemporánea (de 1980 a nuestros días)

\title{
La dicotomía de lo legible e ilegible en la literatura argentina contemporánea, o El lado oscuro de Carlos Gamerro
}

\section{Claudia Hammerschmidt}

\section{OpenEdition}

\section{Journals}

Electronic version

URL: http://journals.openedition.org/lirico/3897

DOI: $10.4000 /$ lirico.3897

ISSN: 2262-8339

Publisher

Réseau interuniversitaire d'étude des littératures contemporaines du Río de la Plata

Electronic reference

Claudia Hammerschmidt, « La dicotomía de lo legible e ilegible en la literatura argentina contemporánea, o El lado oscuro de Carlos Gamerro », Cuadernos LIRICO [En línea], 17 | 2017, Puesto en línea el 17 diciembre 2017, consultado el 05 mayo 2019. URL : http://journals.openedition.org/ lirico/3897 ; DOI : 10.4000/lirico.3897

This text was automatically generated on 5 May 2019.

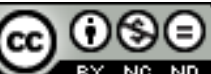

Cuadernos LIRICO está distribuido bajo una Licencia Creative Commons Atribución-NoComercialSinDerivar 4.0 Internacional. 


\title{
La dicotomía de lo legible e ilegible en la literatura argentina contemporánea, o El lado oscuro de Carlos Gamerro
}

\author{
Claudia Hammerschmidt
}

1 Pensar la literatura argentina contemporánea, y en este caso las novelas de Carlos Gamerro, en su tensión entre lo legible y lo ilegible, vuelve a relacionarla con el dilema de la modernidad literaria y la dicotomía básica inherente a su lenguaje. Esta dicotomía, es decir la tensión entre realidad y autorreferencialidad, o la tendencia simultánea hacia el polo referencial y la dimensión autónoma del lenguaje, había sido uno de los tópicos del altomodernismo, reflejada en obras como Ulysses de Joyce, El hombre sin atributos de Musil, o Adán Buenosayres de Marechal. Esta simultaneidad de un deseo de representar el mundo exterior y la lucha por liberarse de la obligación de decir el mundo, tan característica de la producción literaria de la primera mitad del siglo XX, parece volver a surgir en su final, en una Argentina posdictatorial y neoliberal que a primera vista poco se presta a las preocupaciones estéticas de una generación que había llevado a la narración a sus propios límites: a esta región semiótica donde los signos y las cosas se separan de modo tal que conducen a la ilegibilidad tanto de la realidad como de las palabras. ${ }^{1}$ Afirmar la ilegibilidad de autores como Carlos Gamerro, entonces, cuyo lenguaje a primera vista parece indicar una vuelta a la historia y narración tradicional en su supuesta sucesividad y teleología, implica leer en su llamada 'epopeya argentina'² la inscripción de la lucha permanente de los signos entre la voluntad de traducir y de sustraerse al mundo. E implica también que en novelas como Las Islas (1998) reaparece este gran dilema del altomodernismo que consiste en ilustrar la tensión paradójica hacia el mundo significado y hacia el propio acto de la significación, poniendo así en escena la dicotomía de la traducción y traición, inherente a toda referencia, y exponiendo a la vez la inclinación del lenguaje a ilustrar su performatividad significante. Pues si por un lado los signos literarios pertenecen al sistema lingüístico y no pueden sustraerse ni a su función comunicativa ni a su valor o posición que tienen u ocupan en las relaciones sintagmáticas 
y paradigmáticas del texto, por el otro, constantemente luchan por su autonomía o libertad relativa dentro del misma sistema expresivo al que pertenecen, como lo había ilustrado sobre todo la literatura del altomodernismo, y como lo vuelve a escenificar la literatura de un autor tan 'épico' y supuestamente realista como lo es la de Gamerro.

2 Para situar entonces la escritura de Carlos Gamerro en esta tensión 'moderna' entre lo legible y lo ilegible, quiero primero detenerme en esta dicotomía y recordar muy brevemente y a modo de ejemplo tres de las conocidas posiciones teóricas que en los años 60 y 70 se desarrollaron con respecto a lo 'ilegible' de la literatura.

3 En sus análisis de textos literarios de los siglos XIX o XX como À la recherche du temps perdu de Marcel Proust, Paul de Man destaca sobre todo la indecidibilidad del lenguaje literario moderno, dividido entre un sentido literal, directo, dado, y este otro, retórico, alegórico, que interminablemente aumenta las lecturas e impide que se llegue a constituir un sentido definitivo o legible. ${ }^{3}$ Lo que según de Man amenaza el significado de los textos y causa su ilegibilidad es la simultaneidad de sus dimensiones semiológicas y retóricas, cognitivas y performativas. Es por esta duplicidad inherente a su significación que, según el teórico belga de Yale, la literatura moderna pone en escena su intrínseca apertura infinita - o su constante e insoslayable alegoría de la lectura, que desintegra y disuelve todo sentido en un « systematic undoing [...] of understanding »4.

4 Michel Foucault, para quien la literatura moderna constituye «la transgresión y el tránsito más allá de la muerte ${ }^{5}$, la considera sobre todo como «expérience limite »: « cette entreprise de 'dé-subjectivation', cette 'idée d'une expérience limite qui arrache le sujet à lui-même' $»^{6}$. Esta literatura contradiscursiva no confiere sentido o coherencia, sino que los diluye. Es ilegible porque hace experimentar « el hueco del lenguaje »: « un lenguaje que es ausencia, que es asesinato, que es desdoblamiento, que es simulacro $»^{7}, \mathrm{y}$ que entonces sustrae toda seguridad epistemológica y ontológica al sujeto, autor o lector, porque se erige sobre las ruinas de una presencia perdida, que solo surge cual fantasma de entre los escombros.

5 Roland Barthes, finalmente, en su famoso estudio sobre el " plaisir du texte », subraya la « duplicité » de la literatura moderna ${ }^{8}$, dividida entre dos lados opuestos: « un bord sage, conforme, plagiaire [...], et un autre bord, mobile, vide [...]: là où s'entrevoit la mort du langage $"^{9}$. Son estos dos lados los que Barthes designó como lo legible - "régi par le principe de non-contradiction $»^{10}$, donde "tout se tient, tout doit se tenir $»^{11}$ y lo escribible -donde prevalecen la disolución de estructuras, la subversión y la pérdida ${ }^{12}$. Para Barthes, entonces, lo ilegible o "scriptible » se define por lo que se sustrae a lo semiológico; constituye su lado oscuro, casi un punctum ${ }^{13}$ que rompe con el régimen representativo de los signos: lo que atrae, fascina, pero también agrede, y siempre amenaza con la disolución o la muerte de autor, lector y sentido.

6 Para los tres teóricos íconos de la modernidad, lo ilegible es, por lo tanto, el aspecto oscuro, extraño, inquietante o unheimlich de la literatura, su resto que vuelve a la superficie para hostigarla y conminarla en su supuesta referencialidad o transitividad, que le inscribe su muerte y vuelve su sentido intrínsecamente indecidible. Y es esta dimensión subterránea, autónoma, incontrolable e indecidible del lenguaje la que para los tres teóricos posestructuralistas no solo produce su ilegibilidad, sino que también supera el trabajo del autor y convierte a éste en víctima de su propio producto.

7 En los diversos textos literarios, sin embargo, como sobre todo Foucault y Barthes siempre volvieron a destacarlo, esta ilegibilidad se pone en escena de manera muy 
heterogénea. Así como existen manifestaciones literarias en donde el autor se entrega voluntaria o placenteramente a la fuerza incontrolable del lenguaje que lo excede, hay otras en las que se lucha por el control y se intenta fortalecer el lado referencial del texto. Estas últimas nacen sobre todo en momentos en los que la literatura intenta anteponer su función social y comunicativa a su dimensión autorreferencial y autónoma, opta por el «j'accuse », y programáticamente denuncia, visibiliza o memoriza violencias discursivas, injusticias sociales, o crímenes cometidos por o en nombre del Estado.

Obviamente, este es el caso sobre todo en momentos que siguen a grandes crisis como las dictaduras con sus silenciamientos $\mathrm{u}$ oscurecimientos estratégicos del sentido. $\mathrm{Y}$ no asombra que la literatura argentina inmediatamente posterior al llamado " proceso » de 1976 a 1983, escrita por sus participantes directos, en gran parte haya intentado suprimir la dimensión autónoma del lenguaje y haya reaccionado contra toda apariencia de ilegibilidad o falta de referencialidad, asociada en 1983 claramente a la elusión de la censura política, vigente hasta ese momento en la Argentina del proceso. Después de la larga experiencia del 'insilio' de autores argentinos que habían debido tapar, desviar o desfigurar el significado de sus textos para seguir publicando y viviendo en su país, a partir de 1983 su producción literaria mayoritariamente tiende a la referencialidad directa. ${ }^{14}$ Se escriben textos que intentan negar el lado oscuro del lenguaje, que quieren testimoniar, rescatar la historia, decirlo todo explicitándolo, tratando de evitar todo silencio o reticencia. ${ }^{15}$ Como lo resalta el mismo Carlos Gamerro en su análisis de la diferencia entre la literatura de la primera y la segunda generación posdictatorial, en los años inmediatamente posteriores a 1983 lo alusivo, insinuado, metafórico, podían incluso volverse ideológicamente sospechosos: «lo indirecto, lo retaceado, lo sesgado, lo murmurado podía sugerir alguna forma de complicidad con los modos de ocultamiento o parcelamiento de la época dictatorial, un tabicamiento narrativo $»^{16}$.

9 Constatar entonces la vuelta de lo ilegible en la producción literaria argentina a fines del siglo XX, podría implicar afirmar una oposición exclusiva entre una primera generación posdictatorial que rechazó el ocultamiento y proclamó un discurso realista, directo, refractario a lo retórico o alusivo; y otra generación más contemporánea, que, saturada del discurso de los hechos ${ }^{17}$, reaccionó a su vez contra la pretensión de legibilidad y expresión explícita para volver a entregarse a este otro lado del lenguaje literario, admitir la indecidibilidad del sentido, y ceder al deslizamiento del significado bajo el significante, volviendo la oscuridad o el hermetismo el programa estético de toda una generación que creció con una literatura de denuncia.

10 Sin embargo, al hablar de lo ilegible como gesto ostensible de la literatura argentina contemporánea, y basándome concretamente en Carlos Gamerro, quiero plantear otra hipótesis. Entiendo la vuelta de una estética de lo ilegible como un acto deliberado que relaciona la indecidibilidad, ausencia o desaparición del sentido inherente al lenguaje con su temática: la crítica ideológica, política y social de la Argentina posdictatorial y neoliberal, y entonces con su pretensión de decir el mundo. Leo la vuelta de lo ilegible en autores como Gamerro como una tendencia que, a finales del siglo XX y a principios del XXI, exacerba programáticamente el vacío constitutivo del lenguaje moderno y lo aprovecha. Al mismo tiempo pretendo mostrar que, al combinar la ausencia y violencia inherente a la escritura con los horrores reales que intenta representar, esta escritura llega a hacer responderse los dos lados del lenguaje, el referencial y el autónomo, y se acerca así a decir lo indecible y dar a leer lo ilegible. O, dicho de otra manera, pretendo que la puesta en escena de la bidimensionalidad de los signos se aprovecha de la 
indecidibilidad del lenguaje, de su propensión a la transgresión y al duelo, para decir el terror. Así, una literatura como la de Gamerro expone la distancia que la separa de las cosas, su «hueco » o su «punctum », para decir las transgresiones políticas, sociales y morales acometidas por el estado e inscribir a las víctimas, los desaparecidos y ausentes, en la misma « expérience limite » 0 « muerte » implicada por la escritura moderna.

De esta manera, propongo considerar a Gamerro como productor de una escritura 'estrábica'. Esta escritura de mirada doble, torcida, oblicua, se aprovecha programáticamente de la "duplicité » del signo lingüístico (de su lado referencial y a la vez de su resto ilegible) para denunciar las transgresiones político-sociales de la historia política argentina y poner al mismo tiempo su propia referencialidad en entredicho.

12 En su libro de ensayos Ficciones barrocas de $2010^{18}$, y basándose en teóricos como Foucault y Deleuze, Carlos Gamerro explica el barroco como reacción a la crisis de la representación que separa la episteme renacentista de la del siglo XVII:

En el renacimiento el poder representativo de los signos [...] se da por sentado [...]. La representación [...] no se problematiza o se cuestiona: se ejerce. El barroco surge cuando esta confianza se resquebraja [...]. Las cosas pertenecen al mundo y las palabras a los hombres, y los hombres, al establecer relaciones entre signos y referentes, yerran. Ya no hay garantía divina. La semejanza, base del conocimiento renacentista, es en el barroco ilusión y ocasión de error. ${ }^{19}$

13 Esta crisis se manifiesta, según Gamerro, en dos modos distintos de ser barroco: en la « escritura barroca » que, a la manera de Góngora, se distingue por un exceso del lenguaje y de sus recursos retóricos; y en la "ficción barroca » que, a la manera de Cervantes, complica las estructuras narrativas a través de su entrecruzamiento. Este segundo caso se caracteriza por la superposición de niveles supuestamente opuestos ${ }^{20} \mathrm{y}$ por su intercambiabilidad operada en pliegues y metalepsis que mezclan planos como « ficción/ verdad, cuadro/modelo, copia/original, reflejo/objeto, imaginación/percepción, imaginación/recuerdo, sueño/vigilia, locura/cordura, teatro/mundo, obra/autor, arte/ vida, signo/referente ${ }^{21}$. Estos planos no se oponen - se confunden constantemente para invertir las causalidades involucradas en la representación y construir «una hiperrealidad compleja, inquieta y, sobre todo, autocontradictoria e inconsistente $»^{22}$. De esta manera, " [e]l arte barroco es un arte del fracaso en hacer coincidir palabras y realidad [...]. Es un arte desconfiado por naturaleza, y su atención se dirige menos al mundo que a las variadas representaciones que de él nos hacemos $»^{23}$.

14 A diferencia de la " escritura barroca », la «ficción barroca » de la que habla Gamerro escenifica entonces la " duplicité » del lenguaje, tan discutida en la modernidad literaria, no desde sus significantes y formas lingüísticas, sino de forma temática y estructural. Esta «ficción barroca » siempre vuelve a desconcertar certezas y pone en duda los límites entre la realidad y su representación. Y a pesar de que Gamerro mismo aplique esta categoría a los llamados autores 'fantásticos' o narradores vanguardistas rioplatenses de los años 1940 a 1960, propongo leer su propia novelística según el modelo teórico desarrollado por él y leer en especial su primera novela Las Islas (de 1998) ${ }^{24}$ en su doble tendencia hacia la referencialidad y la ilegibilidad que resulta de la puesta en duda del límite entre realidad y ficción de su « ficción barroca ». 
15 Esta primera novela de Gamerro (como también las otras que se sitúan en momentos clave de la historia política del país ${ }^{25}$ ) se mueve entre la denuncia explícita y una compleja estructura narrativa que, en la proliferación sintáctica de un lenguaje supuestamente lineal y referencial, provoca momentos de pérdida, intransitividad e ilegibilidad del texto. De esta manera, mi hipótesis, no solo combina la denuncia con una mise-en-abyme barroca, sino que también funcionaliza la simultaneidad del lado referencial y autónomo del lenguaje, su lado legible y este otro donde el significado se pierde, para hablar tanto de las víctimas de la dictadura o de la guerra de Malvinas como también de las víctimas del lenguaje, que siempre da vuelta a lo que no puede decir y pone al que habla en un abismo del que casi no hay escapatoria.

Las Islas -summa de la historia argentina del siglo XX que ya por su excesiva extensión se mueve en el límite de la legibilidad y casi la desborda- se incluye en los proyectos épicos modernos al estilo de Joyce, Musil o Marechal y puede al mismo tiempo considerarse la gran farsa épica ${ }^{26}$ de la Guerra de las Malvinas. Ya que por un lado presenta los diferentes discursos operativos en los relatos sobre la guerra ${ }^{27}$, y por el otro pone en escena la autonomía del lenguaje y la imposibilidad de la representación tan presentes en el altomodernismo y que hasta hoy ocupan a su autor. Porque al representar los discursos ajenos, Las Islas reflexiona simultánea y meta-estéticamente sobre su propia imposibilidad representacional, haciendo coincidir de esta manera la aporía de la escritura con el problema del narrador de decir el trauma y la pérdida sufrida por la guerra. En una narración paranoica donde se superponen mundos virtuales potenciados y se pierde la distinción entre copia y original, reflejo y objeto, imaginación y recuerdo, también se superponen las proliferaciones de una escritura y ficción barrocas que envuelven a su protagonista-narrador sin que pueda escapar del laberinto.

17 Las Islas narra de forma autodiegética la búsqueda detectivesca del hacker Felipe Félix, contratado por el multimillonario Fausto Tamerlán para encontrar a los testigos del asesinato cometido por César, el hijo menor del dueño de las torres. La historia básica, entonces, que mezcla distintos géneros como el thriller o la distopía posmoderna, no se ubica en las islas, presentes desde el título, sino en el Buenos Aires menemista neoliberal de 1992, diez años después de la guerra de las Malvinas. Ésta, sin embargo, aunque ausente en el tiempo y en el espacio de la historia básica, siempre se inscribe en el texto, donde sigue sucediendo en varios niveles de la narración ${ }^{28}$ - sobre todo en la memoria traumatizada de los protagonistas, todos ellos mutilados por la experiencia de la guerra y/o de la dictadura militar y marcados por sus huellas hasta en su propia piel. ${ }^{29}$ Así, la guerra y la dictadura se inscriben en los cuerpos, apareciendo y desapareciendo en una escena de la que supuestamente están ausentes y afectándola por su irreprimible presencia o constante retorno.

18 Los personajes de Las Islas, entonces, con sus cuerpos y psiques lesionados, representan no la vida contemporánea, sino la supervivencia. Aún diez años después de la guerra y nueve después del 'proceso', sus víctimas no son más que simulacros de vida, vivosmuertos que cual zombis deambulan en una sociedad que reemplazó « el control estatal [...] por el control empresarial $»^{30} \mathrm{y}$ donde alguien -el autodenominado superhombre, 'Big Brother' o Dios Fausto Tamerlán en la cima de su panóptico o torre empresarial hecha de 
vidrios y espejos (el espejo, "el archibarroco motivo ", como lo llama Gamerro en Ficciones barrocas ${ }^{31}$ )- tiene el poder absoluto e intenta controlarlo todo. ${ }^{32}$

19 Ya en el delirante primer capítulo que presenta la llegada de Felipe a las torres kafkianas de Tamerlán, se pone en escena el frenesí de Fausto por crear su doble perfecto ${ }^{33}$, queriendo volver a concebir a su hijo hasta que salga a su imagen y semejanza. ${ }^{34}$ Así como intenta controlar su sangre y sus genes, sueña con una nueva era o tercera fundación de Buenos Aires con hijos clones de su padre que repitan eternamente «la manía de un orden puro anhelando la perfección eterna del diamante $»^{35}$.

20 El mundo de la torre, entonces, ${ }^{36}$ consecuencia de la guerra donde paternidades, acumulaciones de capital y fundaciones de la nación se revelan como repeticiones o simulacros de un supuesto origen o modelo traumático -Fausto, Malvinas- dado a reproducirse interminablemente, socava el concepto de originalidad y confunde los límites entre vida real, imagen especular y delirio desmesurado de casi todos los personajes. Así, por la perversión $a b$ ovo de Las Islas, la novela pone en escena constantemente la intercambiabilidad de los niveles ontológicos y provoca la indecidibilidad entre original, copia y simulacro.

21 De este mundo virtual, aparentemente no hay escapatoria. El presente, como el cráneo de Felipe herido en la guerra o la espalda de Gloria marcada por la tortura, está doblemente perforado y afectado por los fantasmas del pasado. Estos, por un lado, siguen surgiendo de sus huecos como de entre los muertos, y, por el otro, se perpetúan en un mundo virtual ilimitado. Los muertos no se enterraron completamente, sino que vuelven a aparecer desde un mundo abismal e inquietan un presente íntimamente fisurado, herido. ${ }^{37}$

Simulacros, copias o repeticiones se dan sobre todo en relación a las Islas mismas. Así, el trauma de la pérdida provoca delirios de una segunda oportunidad (de guerra, de recuperación territorial, de vida) como si se tratara de una película que se proyectara de atrás para adelante, y hace soñar con su reproducción exacta en una maqueta sobredimensional que frenara el curso del tiempo:

Tomás [...] procedía de un modo rigurosamente retrospectivo. La solución para él consistía en proyectar la película de Malvinas para atrás para que todo volviera a ser como en los primeros días [...]. Entonces bastaba con detener el film para congelar la imagen en algún día soleado de abril de 1982, cuando las Islas eran definitivamente nuestras y el enemigo tan lejano que nadie creía realmente en su existencia. $^{38}$

[Ignacio] quería reproducir con exactitud cada piedra, cada ventana, cada cerco caído y cada participante individual; lograr como una fotografía en satélite captar cada detalle de esa mañana de abril cuando la guerra era todavía una posibilidad remota, y erigir la perfección de su modelo en un amuleto contra su llegada. Ignacio había descubierto, de manera puramente intuitiva, que el espacio es infinitamente divisible y que mientras uno profundice en esta división puede obligar a mantenerse inmóvil al tiempo. Siempre habría un detalle que agregar a la cada vez más perfecta reproducción de ese maravilloso 30 de abril, y mientras tanto, hasta que este alcanzara su plenitud, el 1 de mayo tendría que esperar. ${ }^{39}$

Lejos de servir de apoyo a la memoria de las Malvinas, el sueño de la vuelta y la maqueta, en vez de hacer volver a la experiencia traumática del pasado, instalan un mundo virtual que niega el tiempo y trata de congelar un momento de frágil victoria antes de que el drama comience. Como Fausto en su torre, estos dispositivos eternizan un sueño donde todo está a punto de suceder sin ocurrir nunca - todo al revés del videogame construido por Felipe, que pretende « ganarle al tiempo no deteniéndolo, sino yendo más rápido que 
él $\aleph^{40}$. La isla de Felipe, entonces, se compone como patchwork de varios juegos en una copresencia espacial que así se deterritorializa:

Elegí la Primera Guerra para los combates terrestres; con sus interminables trincheras de barro y cargas a pie con bayoneta calada era la más parecida a la que nos tocó. Modernicé un poco, igual, los armamentos, sacando los nuestros de la Segunda y la de los Seis Días, de la del Golfo los ingleses. Elegí un paisaje del frente ruso en el 44 [...]; pero los soldados estaban demasiado abrigados para hacer de argentinos. [...] Busqué y busqué, pero al final no encontré nada mejor que los iraquíes [...]; les sacudí un poquito la arena y ya estaban listos para combatir. Sólo me faltaban nuestros barcos, pero fue fácil sacarlos de los archivos de la Segunda Guerra, y algo emocionado tecleé la fecha, 1 de abril de 1982, y lancé la invasión. ${ }^{41}$ aje de Fausto Tamerlán, pasando por infinitas alusiones a Kafka, a Echeverría, a Mallea, a Marechal, a Bioy Casares, a Piglia y siempre a Borges, las referencias intertextuales se acumulan en un texto que pone en escena su artificialidad al querer contar las secuelas de una guerra que, en sí, se inscribe por su propia ausencia en el cuerpo textual que supuestamente la teje. Esta permanente antecedencia de un hecho que renace posteriormente al ser recordado y repetido en el texto, se refleja también en su estructura narrativa. Como todo tiene su doble en esta novela paranoica ${ }^{42}$, también diría que el texto tiene dos partes que de alguna manera se reflejan mutuamente. $Y$ aunque ya los capítulos I a VII de los XVI en total siempre se refieren a las Islas, es recién a partir del capítulo VIII cuando Felipe rompe con su mutismo e incorpora sus propios recuerdos al relato de Malvinas.

esta manera, tanto como la piel de los ex combatientes o las víctimas de las torturas tienen costras y cicatrices que al mismo tiempo protegen y siguen marcando el daño, también el texto se presenta como caparazón o narración delirante que sigue tapando las heridas, bocas o huecos y que simultáneamente vuelve a abrir las llagas, dañando y curando así al cuerpo o significado por su misma insistencia. Es lo podrido, reprimido, indecible lo que insiste en repetirse y lo que el texto a la vez calla, omite y vomita:

[C]ometí el error de abrir la boca para tomar aire y todo salió disparado en dos chorros sobre las revista abiertas. [...]. [s]in náusea previa, un reflejo de mi estómago volvió a expulsar todo hacia fuera. Empecé a gemir, muy fuerte, porque ahora estaba demasiado chirle para recogerlo con la mano, así que lo sorbí directamente del piso, en cuatro patas, el dolor pateando y aullando como un loco en una celda acolchonada cada vez que bajaba la cabeza, y tapándome la boca con la mano saqué del cajón un rollo de cinta plateada de cuatro centímetros de ancho [...] que usé para sellarme la boca. Ahora, le dije -mentalmente, claro-, te vas a quedar adentro de una vez y cada vez que una arcada me llenaba la boca volvía a tragar, hasta que me caí doblado en el piso, exhausto, la mejilla de costado sobre las revistas embarradas, y me quedé dormido sobre el mapa de las Islas. ${ }^{43}$

Consecuentemente, será la palabra la que, en la segunda parte de la novela, logrará la transformación del caparazón de Felipe. Su relato se interrumpirá cada vez más por flashbacks hacia un tiempo anterior que subsiste como recuerdo, sueño o cicatriz en el presente de la narración. Esta, de alguna manera, se agujerea, se vuelve permeable para 
transformarse en confesión o teatro de la memoria, dando así lugar al renacimiento y a la esperanza de una « recuperación de las Islas $»^{44}$ dentro y al final del mismo texto.

Porque será recién al final cuando Félix logre hablar de sus experiencias - sin que por esto salga definitivamente de su pesadilla o llegue a traducir totalmente lo vivido. Siempre subsiste algo no decible, no legible, un resto o hueco que no se descifra en la narración. Nunca logrará salir completamente del laberinto. Ya que, después de que en el anteúltimo capítulo el narrador finalmente haya narrado los hechos traumáticos en « La batalla de Longdon $\gg^{45}$ que siempre había aplazado y pospuesto, la novela termina con «La recuperación de las Islas » mediante un cuento de hadas alegórico de significado indecidible y final abierto que a su vez vuelve a referir al epígrafe y comienzo del texto. Así, la novela logra decir el trauma y al mismo tiempo expresa la inevitable posterioridad, simulación e imposibilidad de narrar una experiencia traumática que nunca ocurrió de la forma en que se representa y que se sustrae continuamente a su simbolización, legibilidad o decidibilidad. De esta manera, sin embargo, dice la imposibilidad de dominar al lenguaje y de hacerlo decir lo que debe expresar, en el mismo momento en que pone en escena el « hueco » o resto ilegible de su propio discurso. Al poner en escena un texto-vómito que simultáneamente retiene, transforma y repite lo vivido, Gamerro se aprovecha programáticamente de lo indecidible (de Man), asesino (Foucault) y vacío (Barthes) del lenguaje para exorcizar experiencias límites y un mundo devenido ilegible.

29 En conclusión, el lenguaje, en Las Islas, está marcado por la misma ambivalencia o «duplicité » de la que hablaron Barthes, Foucault o de Man al describir lo ilegible de la literatura moderna. Sin embargo, y a diferencia de esta, la escritura 'estrábica' de Gamerro, doble, torcida, oblicua, se aprovecha programáticamente de los dos lados del signo lingüístico, el referencial y el autónomo, para denunciar las transgresiones políticosociales de la historia política argentina y poner al mismo tiempo su propia referencialidad en entredicho. De esta manera, podría decirse, lo ilegible, al exponerse, se transforma en legibilidad de lo indecible que pone en escena, y se hace la expresión más apropiada de la lesión que marca toda la narración. El texto, a pesar de su organización clara y lógica, se vomita, repite lo reprimido, y es así tanto indicio del mal que refleja, seña de su propia putrefacción, como también inicio de su curación. Así, la ilegibilidad misma se vuelve dispositivo de denuncia, que logra a la vez decir el mundo y escenificar su propia autorreferencalidad. Paralelamente, su estructura y tema hacen de la novela una "ficción barroca " en el sentido del mismo Gamerro. La frontera débil, siempre transgredida, entre realidad y virtualidad, original y copia, verdad y ficción, así como las imágenes espectrales y el paso permanente entre presente y pasado (del que vuelven los muertos y las experiencias traumáticas), transforman la novela de Gamerro a la vez en un monumento para las víctimas y en un texto-monstruo, oscuro, que se sustrae a la legibilidad o decidibilidad de un significado. Pero los peligros de este lenguaje son a la vez la posibilidad de la salvación: ya que es en los pliegues, huecos y ausencias que se le ofrece al narrador la posibilidad de decir su trauma, y es en el umbral entre un mundo real y su simulacro donde se expone su turbación.

30 Por consiguiente, el resultado de la búsqueda de Felipe no es la reconstrucción de ningún plan de origen fáustico, sino la narración misma de Las Islas como testimonio de una supervivencia o simulacro. Esta narración, sin embargo, al hacer coincidir el final, el 
relato de Malvinas hecho finalmente por Felipe a Gloria, con la novela misma de Las Islas desde su inicio (que así siempre se convierte en un incipit " in medias res »), se transforma en una cinta de Moebius donde las dos historias, la de 1992 y la de 1982, «habían terminado por fundirse en una como dos ríos $»^{46} \mathrm{y}$ donde el fin, en una parodia implícita a Cien años de soledad, nos remite otra vez al comienzo, y así sucesivamente:

Ahora me encontraba en su misma situación [como la de Ignacio; C.H.], la de demorar lo más posible el final, porque había comprendido que cuando recorrieran las últimas calles las palabras de mi relato, cuando en su interminable marcha mis pies cansados encontraran el centro vacío y de ahí se dejaran llevar hasta la puerta pintada de verde y atravesándola inexorablemente me condujera hasta este sofá donde estaba ahora sentado, el círculo se habría cerrado por fin [...]. Ahora entendía el sentimiento que había comenzado a inundarme desde las primeras palabras de mi relato, el sentimiento no blanco sino pardogrisverdoso en el que habían terminado por fundirse todos los otros a medida que el espectro giraba cada vez a mayor velocidad: era la tristeza indefinible de la despedida. No volvería en diez años más a repetir a contar otra vez la triste historia dos veces vivida, no agregaría otra torsión a la cinta de Moebius que serpenteando entre dos mundos vueltos uno como dos espejos enfrentados había terminado por encontrarse meramente a sí misma. ${ }^{47}$

En este pliegue final (que insiste, de cierta manera, metalépticamente en una «Continuidad de los parques » a la manera de Cortázar, poniendo al descubierto el entrelazamiento de los discursos y de las historias), Gamerro produce su « ficción barroca " como « un compuesto calidoscópico, siempre cambiante, que surge de todas estas combinaciones y entrecruzamientos » para formar « una hiperrealidad compleja, inquieta $\mathrm{y}$, sobre todo, autocontradictoria $»^{48}$, en la que ocurre un " gradual reemplazo del mundo real por el mundo de las representaciones $»^{49}$.

32 En una escritura estrábica que siempre duplica, tuerce y desdibuja lo que ve, la novela se hace cinta de Moebius que representa su objeto al poner en escena su misma ausencia. Al aprovecharse del resto indecifrable del lenguaje para visualizar su vacío, hueco o falta, esta escritura doble, oblicua, dice la imposibilidad de dominar al lenguaje en el mismo momento en que escenifica el resto ilegible de su propio discurso. En esta estrategia estrábica, entonces, consiste la puesta en escena de la ilegibilidad de Las Islas, y en esta exacerbación programática del vacío constitutivo del lenguaje moderno, la vuelta de lo ilegible y el lado oscuro de las ficciones barrocas de Gamerro.

\section{BIBLIOGRAPHY}

Amar Sánchez, Ana María. El relato de los hechos. Rodolfo Walsh: testimonio y escritura. Rosario :

Beatriz Viterbo, 1992.

Barthes, Roland. La chambre claire. Note sur la photographie. Paris : Seuil, 1980.

Barthes, Roland. Le plaisir du texte. Paris : Seuil, 1973.

Barthes, Roland. S/Z. Paris : Seuil, 1970. 
de Man, Paul. Allegories of Reading. Figural Language in Rousseau, Nietzsche, Rilke, and Proust. New Haven and London : Yale University Press, 1979.

Echevarría, Sol, « Carlos Gamerro: Las Islas ». Blogspot: Los asesinos tímidos 8, 2008, disponible en http://asesinostimidos.blogspot.com.ar/2008/08/las-islas-carlos-gamerro-por-sol.html, página consultada el 6/03/ 2017.

Foucault, Michel. De lenguaje y literatura, ed. Ángel Gabilondo, trad. Isidro Herrera Baquero. Barcelona : Paidós, 1996, p. 63-103.

Foucault, Michel. Entretien avec Michel Foucault. En Dits et écrits II, 1976-1988, ed. Daniel Defert y François Ewald, en colaboración con Jacques Lagrange. Paris : Gallimard, 2001.

Gamerro, Carlos. « Sordos ruidos oír se dejan », Facundo o Martín Fierro. Los libros que inventaron la Argentina. Buenos Aires : Sudamericana, 2015, p. 475-488.

Gamerro, Carlos. « Entrevista a Carlos Gamerro. 62/ Clase para desarmar ». Blogspot: Los asesinos tímidos 8, 2008, disponible en http://asesinostimidos.blogspot.de/2008/08/entrevista-carlosgamerro.html, página consultada el 6/03/2017.

Gamerro, Carlos. El secreto y las voces. Buenos Aires : Norma, 2002.

Gamerro, Carlos. El sueño del señor juez. Buenos Aires : Norma, 2000.

Gamerro, Carlos. Ficciones barrocas. Una lectura de Borges, Bioy Casares, Silvina Ocampo, Cortázar, Onetti y Felisberto Hernández. Buenos Aires : Eterna Cadencia, 2010.

Gamerro, Carlos. Las aventuras de los bustos de Eva. Buenos Aires: Norma, 2004.

Gamerro, Carlos. Las Islas. Buenos Aires: Norma, 2007.

Gamerro, Carlos. Un yuppie en la columna del Che Guevara. Buenos Aires: Edhasa, 2011.

Garramuño, Florencia. La experiencia opaca. Literatura y desencanto. Buenos Aires : Fondo de Cultura Económica, 2009.

Kohan, Martín. «El fin de una épica ». En: Punto de vista. Revista de cultura 64, 1999, p. 6-11.

\section{NOTES}

1. Cfr., aunque dedicado a la crítica del altomodernismo en autores posteriores como Juan José Saer, el brillante análisis del dilema moderno que presenta Florencia Garramuño en La experiencia opaca. Literatura y desencanto, Buenos Aires : Fondo de Cultura Económica, 2009.

2. Así puede entenderse la continuación temática entre gran parte de las novelas de Gamerro, como Las Islas (1998), El sueño del señor juez (2000), El secreto y las voces (2002), Las aventuras de los bustos de Eva (2004), o Un yuppie en la columna del Che Guevara (2011), todas ellas relacionadas entre sí y ubicadas en momentos cruciales de la historia política y económica argentina: la lucha entre 'civilización y barbarie' que funda los pueblos 'del interor'; el peronismo; la guerrilla; la dictadura militar; la guerra de las Malvinas; el neoliberalismo.

3. Cfr. Paul de Man, Allegories of Reading. Figural Language in Rousseau, Nietzsche, Rilke, and Proust, New Haven and London : Yale University Press, 1979.

4. Paul de Man, Ibidem, p. 301.

5. Michel Foucault, De lenguaje y literatura, ed. Ángel Gabilondo, trad. Isidro Herrera Baquero, Barcelona : Paidós, 1996, p. 63-103; p. 71.

6. Michel Foucault, Entretien avec Michel Foucault. En: Dits et écrits II, 1976-1988, ed. Daniel Defert y François Ewald, en colaboración con Jacques Lagrange, Paris : Gallimard, 2001, p. 862. 
7. Michel Foucault, Lenguaje y Literatura, op. cit., p. 65 y 66.

8. Roland Barthes, Le plaisir du texte, Paris : Seuil, 1973, p. 15.

9. Roland Barthes, Ibidem, p. 14-15.

10. Roland Barthes, S/Z, Paris : Seuil, 1970, p. 162.

11. Roland Barthes, Ibidem, p. 187.

12. « Le bord subversif [...] est celui de la violence; mais ce n'est pas la violence qui impressionne le plaisir; la destruction ne l'intéresse pas; ce qu'il veut, c'est le lieu d'une perte, c'est la faille, la coupure, la déflation, le fading qui saisit le sujet au cœur de la jouissance » (Roland Barthes, Le plaisir du texte, op. cit., p. 15).

13. Cfr. Roland Barthes, La chambre claire. Note sur la photographie, Paris : Seuil, 1980, p. 49: «Ce second élément [...], je l'appellerai donc punctum; car punctum, c'est aussi: piqûre, petit trou, petite tache, petite coupure - et aussi coup de dés. Le punctum d'une photo, c'est ce hasard qui, en elle, me point (mais aussi me meurtrit, me poigne). »

14. Como bien se sabe, esta voluntad de referir el mundo directamente no es la única posición estética de los años 80 y 90, como lo demuestran autores con tendencia autorreferencial como Perlongher o Aira.

15. Como ejemplos, se pueden citar el famoso informe Nunca más (1984), pero también Recuerdo de la muerte (1984) de Miguel Bonasso o, ya más tarde, La voluntad (1997-1998) de Martín Caparrós y Eduardo Anguita.

16. Carlos Gamerro, «Sordos ruidos oír se dejan », Facundo o Martín Fierro. Los libros que inventaron la Argentina, Buenos Aires : Sudamericana, 2015, p. 475-488; p. 475.

17. Para esta noción, cfr. el ya clásico trabajo de Ana María Amar Sánchez, El relato de los hechos. Rodolfo Walsh: testimonio y escritura, Rosario : Viterbo, 1992.

18. Carlos Gamerro, Ficciones barrocas. Una lectura de Borges, Bioy Casares, Silvina Ocampo, Cortázar, Onetti y Felisberto Hernández, Buenos Aires : Eterna Cadencia, 2010.

19. Carlos Gamerro, Ibidem, p. 27. Considerado desde este punto de vista, el barroco es un arte extremadamente moderno, y no asombra que resurja en estéticas como el neobarroco cubano (Alejo Carpentier, Lezama Lima, Severo Sarduy, Guillermo Cabrera Infante) o el neobarroso argentino (Perlongher).

20. «[L]o característico del barroco es su afición, adicción a veces, al juego de intercambiar, plegar o mezclar [...] los distintos planos de los que la realidad se compone » (Carlos Gamerro, Ibidem, p. 18).

21. Carlos Gamerro, Ibidem, p. 18.

22. Carlos Gamerro, Ibidem, p. 18.

23. Carlos Gamerro, Ibidem, p. 28.

24. Se citará según la segunda edición en Norma: Gamerro 2007.

25. Cfr. El sueño del señor juez, 2000; El secreto y las voces, 2002; Las aventuras de los bustos de Eva, 2004; Un yuppie en la columna del Che Guevara, 2011; cfr. al respecto también la nota 2 que se refiere a la 'epopeya argentina' de Gamerro.

26. Según Kohan, es justamente en Las Islas donde se cruzan el drama y la farsa de la guerra (Martín Kohan, «El fin de una épica », Buenos Aires: Punto de vista. Revista de cultura 64, 1999, p. 6-11).

27. Cfr. Carlos Gamerro en una entrevista: « En mi caso la novela trabaja sobre los discursos, no sobre la guerra » («Entrevista a Carlos Gamerro. 62/ Clase para desarmar », Blogspot: Los asesinos tímidos 8, 2008, disponible en http://asesinostimidos.blogspot.de/2008/08/entrevistacarlos-gamerro.html, página consultada el 6/03/2017).

28. Por ejemplo, en la esperanza de los ex combatientes de retornar a las islas en una segunda oportunidad; o en el videogame programado por Felipe Félix para el mayor Verraco en el que supuestamente siempre ganarán los argentinos. 
29. Sea el loco Emilio en el Borda, que repite eterna e ininteligiblemente el diario de la guerra del mítico héroe de Malvinas, el mayor X alias Arturo Cuervo; sea Gloria, la mujer torturada, violada, preñada y desposada por este mismo mayor durante el proceso, con su piel cubierta de infinitas cicatrices por las que todavía se sienten fluir las corrientes eléctricas de la picana; o sea el yo narrador Felipe Félix mismo, marcado por las batallas mediante un fragmento de su propio casco metálico de la guerra que se le incrustó en el cráneo como continuo recuerdo de algo que no quiere recordar.

30. Sol Echevarría, "Carlos Gamerro: Las Islas ", Blogspot: Los asesinos tímidos 8, 2008, disponible en http://asesinostimidos.blogspot.com.ar/2008/08/las-islas-carlos-gamerro-porsol.html, página consultada el 6/03/2017.

31. Carlos Gamerro, Ficciones barrocas, op. cit., p. 41.

32. Los mecanismos del poder dictatorial han cambiado de procedimiento, pero siguen en pie, como siguen manejándolos los mismos funcionarios, militares de la dictadura y oficiales de la guerra. Así, temas como la paternidad, el linaje, la repetición del modelo mediante el hijo como copia se relacionan directamente con la puesta en escena del discurso nacionalista al alucinar una continuidad subterránea de valores provenientes de la 'Argentina invisible', que desciende del homo argentinus de Florentino Ameghino y que es conducida por una « comunidad argentina ideal » ubicada en las Islas. Como las voces le sugieren al mayor X, es esta comunidad la que, tal como el grupo de los ex combatientes que prepara la vuelta a las Malvinas, está ideando una nueva sociedad, un nuevo 'Nuevo Mundo' con un régimen fascista basado en la esclavitud y en el control estatal piramidal. Lo que en el diario de la guerra del mayor parece provenir del delirio galopante provocado por las privaciones de la guerra, se reproduce en los sistemas económicos e incluso arquitecturales de las empresas actuales. Aquí, la organización piramidal se repite tanto en la arquitectura de las torres de vidrios y espejos como en el funcionamiento del nuevo mercado neoliberal: pirámides todos ellos donde, como en las torres en su versión actualizada del panóptico de Bentham, más se ve, más poder se tiene y menos se expone a la mirada de los demás que trabajan como nuevos esclavos para un jefe-dios omnisciente y escondido.

33. Que recuerda el homunculus del Fausto de Goethe.

34. Cfr. Carlos Gamerro, Las Islas, op. cit., p. 35.

35. Carlos Gamerro, Ibidem, p. 30.

36. Que obviamente no solo recuerda las altas torres símbolos de la modernidad, sino también la torre barroca calderoniana, con un Segismundo prisionero entre vida y sueño.

37. Cfr. el surgimiento de los cuatro amigos, muertos en la guerra, en la calle Malvinas Argentinas (Carlos Gamerro, Ibidem, p. 478-482).

38. Carlos Gamerro, Ibidem, p. 56. Cfr. también la continuación de la cita: " Los diez mil prisioneros se liberaban en los barcos y volvían a toda máquina hacia la capital de las Islas, que retomaban empujando a los ingleses calle por calle y monte por monte, la tierra volando por cuenta propia a llenar los cráteres y reparar las paredes de las trincheras, la sangre volviendo al cuerpo de los heridos y los muertos levantándose para volver a combatir, obligando al enemigo a retroceder hasta sus barcos y volverse marcha atrás hacia Inglaterra » (Carlos Gamerro, Ibidem, p. 56).

39. Carlos Gamerro, Ibidem, p. 69.

40. Carlos Gamerro, Ibidem, p. 77.

41. Carlos Gamerro, Ibidem, p. 75.

42. Hay dos islas, dos torres, dos hijos Tamerlán, dos nenas (mellizas) de Gloria, dos diarios de guerra, dos versiones del videogame...

43. Carlos Gamerro, Ibidem, p. 90.

44. Así es el título del capítulo 16, que es el último capítulo del libro.

45. Así es el título del capítulo 15.

46. Carlos Gamerro, Ibidem, p. 485. 
47. Carlos Gamerro, Ibidem, p. 485-486.

48. Carlos Gamerro, Ficciones barrocas, op. cit., p. 18.

49. Carlos Gamerro, Ficciones barrocas, op. cit., p. 203.

\section{ABSTRACTS}

In my analysis « The dichotomy of the readable and the unreadable in contemporary argentine literature, or The dark side of Carlos Gamerro ", I understand the return of the unreadable, as it can be found in authors like Gamerro, and especially in his Las Islas (1998), as a tendency that, at the end of the $20^{\text {th }}$ and beginning of the $21^{\text {st }}$ century, programmatically sharpens the constitutive void of modern language in order to use it for its own aims. At the same time, I want to show that, by combining the absence and the violence inherent to writing with the real horror it tries to represent, this writing succeeds in interrelating the two sides of language, the referential one and the autonomous one, and, by doing so, to say the unsayable and to make us read the unreadable. I propose, in other words, that the mise en scène of the bipolarity of signs benefits from the unsayability of language, from its propensity to transgression and pain, to tell us about terror. By doing so, a literature like the one of Gamerro exposes the distance which separates it from the things, its "void" or punctum, in order to express the political, social and moral transgressions committed by the state and to inscribe the victims, the disappeared and the absent, into this very expérience limite, or « death », implied by modern writing.

En mi análisis « La dicotomía de lo legible e ilegible en la literatura argentina contemporánea, o El lado oscuro de Carlos Gamerro ", entiendo la vuelta de lo ilegible en autores como Gamerro, y especialmente en su novela Las Islas (1998), como una tendencia que, a finales del siglo XX y a principios del XXI, exacerba programáticamente el vacío constitutivo del lenguaje moderno y se lo apropia. Al mismo tiempo pretendo mostrar que, al combinar la ausencia y la violencia inherentes a la escritura con los horrores reales que intenta representar, esta escritura hace que ambos aspectos del lenguaje, el referencial y el autónomo, se correspondan, digan lo indecible y den a leer lo ilegible. 0 , dicho de otra manera, pretendo que la puesta en escena de la bidimensionalidad de los signos se apropia de la indecidibilidad del lenguaje, de su propensión a la transgresión y al duelo, para decir el terror. Así, una literatura como la de Gamerro expone la distancia que la separa de las cosas, su « hueco » o su punctum, para decir las transgresiones políticas, sociales y morales acometidas por el estado e inscribir a las víctimas, los desaparecidos y ausentes, en la misma expérience limite o « muerte » que la escritura moderna implica.

Dans notre analyse, « La dichotomie du lisible et de l'illisible dans la littérature argentine contemporaine, ou Le côté obscur de Carlos Gamerro ", nous partons du constat d'un retour de l'illisible chez des auteurs contemporains comme Carlos Gamerro et notamment dans son roman Las Islas (1998); une illisibilité qui, à la fin du XXe et au début du XXIe siècle, tend à exacerber de manière programmatique le vide constitutif du langage littéraire moderne afin de se l'approprier. En même temps, nous nous proposons de montrer que, en établissant un lien entre l'absence et la violence inhérentes à l'écriture et les horreurs réelles que celle-ci essaye de représenter, cette écriture réussit à mettre en relation la fonction référentielle du langage avec son côté autonome. Ainsi, elle rend possible l'énonciation de l'indicible et la lisibilité de l'illisible. Autrement dit, nous prétendons que la mise en scène de la bipolarité des signes s'approprie de 
l'indicibilité du langage, son penchant à la transgression et à la douleur, pour dire la terreur. De cette manière, une littérature comme celle de Gamerro expose la distance qui la sépare des choses, son « vide » ou son punctum, afin de dire les transgressions politiques, sociales et morales commises par l'état, et afin d'inscrire les victimes, les disparus et les absents, dans cette même « expérience limite » ou de « mort » qu'implique la littérature moderne.

\section{INDEX}

Mots-clés: Carlos Gamerro, Las Islas (1998), littérature argentine contemporaine, la violence de l'écriture, retour de l'illisible pour dire l'indicible

Palabras claves: Carlos Gamerro, Las Islas (1998), literatura argentina contemporánea, la violencia de la escritura, la vuelta de lo ilegible para decir lo indecible

Keywords: Carlos Gamerro, Las Islas (1998), contemporary argentine literature, violence of writing, the return of the unreadable to say the unsayable

\section{AUTHOR}

\section{CLAUDIA HAMMERSCHMIDT}

Friedrich-Schiller-Universität Jena

claudia.hammerschmidt@uni-jena.de 